\title{
РОССИЙСКАЯ ПРАКТИКА ГОСУДАРСТВЕННОЙ ПОДДЕРЖКИ ИННОВАЦИОННОГО ПРЕДПРИНИМАТЕЛЬСТВА
}

\section{RUSSIAN PRACTICE OF STATE SUPPORT FOR INNOVATIVE ENTREPRENEURSHIP Muthanna Ali Salem Ali}

Summary: The purpose of this article is to study the Russian practice of state support of innovative entrepreneurship. The objectives of the work are to investigate the level of state support in this area, conduct an analysis of foreign experience, form conclusions regarding development directions for Russia. Research methods - analysis of scientific publications, relevant data, statistical information.

Keywords: state support, innovative entrepreneurship, innovation, intellectual development.

\section{Введение}

$\Pi$ од внедрением инноваций принято понимать преобразование результатов интеллектуальных разработок в какую-либо продукцию и ее последующим внедрением на рынок. Задача государства сводится к тому, чтобы стимулировать этот процесс и координировать действия его участников. Российская экономика находится на пути инновационного развития, с учетом большой доли в структуре экономики предпринимательства его задачей становится принятие нормативноправовых актов в области регулирования и контроля предпринимателей. Остановимся на формах и методах, которыми оказывается государственная поддержка для инновационного развития предпринимательства. Эти формы и методы делятся на две большие группы - с прямым и опосредованным воздействием на инновационное развитие.

В России принята Стратегия инновационного развития, рассчитанная на реализацию к 2020 г. Документом предусматривается обеспечение соответствия продукции, выпускаемой российскими предприятиям, международным стандартам в области качества и экологии. Только за последние несколько лет РФ поднялась на несколько позиций поднялась в рейтингах, характеризующих условия экономического роста. Так, в рейтинге Doing Business РФ поднялась на 31-е место, хотя еще в 2010 г. занимала лишь 120-е место. Качество экономического роста в России за последние несколько лет тоже улучшилось. Это было обеспечено за счет конкурентноспособности товаров российских производителей на

\author{
Мутхана Али Салем Али \\ Самарский государственный \\ экономический университет \\ ali.muthanna7@gmail.com
}

Аннотация: Цель представленной статьи - исследование российской практики государственной поддержки инновационного предпринимательства. Задачи работы - исследовать уровень государственной поддержки в данной области, провести анализ зарубежного опыта, сформировать выводы, относительно направлений развития для России. Методы исследования - анализ научных публикаций, актуальных данных, статистической информации.

Ключевые слова: государственная поддержка, инновационное предпринимательство, инновации, интеллектуальное развитие.

мировом рынке.

Более того, международное экспертное сообщество признает, что в течение 2010-2019 гг. Россия улучшила свои показатели по инфраструктуре, качеству высшего образования и профессиональной подготовки специалистов наукоемких отраслей. И все же очевиден тот факт, что по уровню развития инноваций РФ серьезно отстает от стран ЕС и США. Улучшение позиций в международных рейтингах во многом обусловлено той политикой государства, которая касается поддержки инноваций в предпринимательской среде [1].

\section{Методология}

В качестве ключевых методов исследования выбран анализ официальных данных рейтинговых агентств статистических данных. Помимо этого, важной основой исследования явилось и анализ научных публикаций по заданной проблеме. Кроме того, обсуждение результатов базировалось на сбор актуальных новостных данных на 2020 год. Также инновационное предпринимательство это относительно новое понятие для современности, соответственно, предпочтение в процессе исследования отдавалось, в большинстве случаев, практическим данным, а не теоретической обоснованности вопроса.

\section{Результаты}

Кроме рейтингов охарактеризовать ситуацию с инновациями можно положением России на высокотехнологичных рынках. По этому показателю Россия всерьез отстает от стран ЕС. Экспертный опрос по теме иннова- 
ций в предпринимательской среде был проведен в 2017 г. На основе его данных были определены те меры поддержки со стороны государства, которые в наибольшей степени повлияли на ситуацию с развитием инновационного предпринимательства. Наиболее существенной мерой поддержки 67\% опрошенных экспертов назвали программы, которые разрабатываются и реализуются Фондом содействия инновациям. $47 \%$ опрошенных экспертов назвали существенной мерой программу, направленную на оказание помощи для инновационных территориальных кластеров. 12\% опрошенных экспертов назвали значимой деятельность центра инноваций «Сколково» [2].

Зато в пользу эффективности программ по поддержке субъектов малого и среднего предпринимательства высказались около 30\% экспертов. Указанные программы были разработаны и продолжают реализовываться при содействии Минэкономразвития. Промышленные предприятия малого и среднего бизнеса, сегодня имеют возможность получить займы от Фонда развития промышленности на разработку и внедрение инноваций на производстве. Более того, инновационному развитию предпринимательства в России способствует программа по созданию технопарков в области высоких технологий. Ситуация с качеством высшего образования и переподготовки специалистов отдельных отраслей за последние годы была улучшена за счет кооперации вузов и предприятий.

Низкие оценки экспертов получили те меры поддержки, которые ориентированы на региональное развитие инновационной среды. Речь идет о программах по развитию инновационной инфраструктуры, программах по созданию технопарков. Низкие оценки экспертов получили конкурсы, которые организуются научными фондами. Объяснить это можно тем, что субъекты предпринимательства научной деятельностью, как правило, не занимаются. По результатам отчета, подготовленного Правительством в 2018 г., была оценена эффективность мер государственной поддержки в отношении инновационного развития предпринимательства [3].

Фактическая результативность отдельных программ (программ поддержки МСП, программ создания инновационных кластеров и программ от Фонда содействия) оказалась выше прогнозируемой. Была отмечена устойчивость полученных эффектов на примере центра «Сколково». Однако в долгосрочной перспективе велика вероятность снижения полученных эффектов от используемых государством мер поддержки. В настоящее время содействие инновационному развитию предпринимательства обеспечивается за счет: программ поддержки в отношении инновационных территориальных кластеров, работы центра «Сколково», кооперациями вузов и предприятий в соответствии с Постановлением со стороны правительства №218, создания технопарков, программ от Фонда содействия инновациям, проектов и фондов от «Роснано», займов от Фонда развития предпринимательства, строительства инновационной инфраструктуры с целью обеспечения инновационной деятельности предприятий в области малого и среднего бизнеса.

Наибольший успех за последние годы достигнут за счет предоставления возможностей для коммерциализации проектов в области инноваций. Есть заметное отставание по финансированию исследований и разработок. Эксперты отмечают, что от этого направления деятельности можно получить лишь краткосрочный эффект в плане инновационного развития предпринимательства. В течение последних лет увеличилась доля субъектов предпринимательской деятельности, которые начали вкладывать инвестиции в развитие человеческого капитала. Политика государства в целях поддержки инновационного развития в первую очередь предназначена для стимулирования инновационной активности в предпринимательской среде [4].

Применение описанных выше мер поддержки оказывает положительное влияние на ситуацию с социально-экономическими показателями. Большая часть программ поддержки инновационного развития принята и реализуется на государственном уровне. В отдельных регионах страны есть собственные проекты по поддержке предпринимательства. Меры поддержки в отношении субъектов предпринимательства в основном носят финансовый характер. К настоящему времени создана необходимая нормативно-правовая база для инновационного развития предпринимательства. Широкое распространение получил инструмент государственных контрактов.

Более того, подготовленные предпринимателями инновационные проекты могут получить финансирование по результатам экспертного отбора. Кадровое обеспечение инновационной деятельности субъектов предпринимательства осуществляется за счет поддержки кооперации вузов и предприятий со стороны государства. Что касается практической помощи со стороны государства, то в отношении субъектов малого и среднего бизнеса ее нельзя назвать сильной. Практически половина из реализуемых в настоящее время программ либо способна принести краткосрочный эффект, либо низко оценивается по показателям эффективности со стороны экспертного общества и самих предпринимателей [5].

Доля инвестиций в сферу научных исследований и разработок со стороны предпринимателей по-прежнему остается низкой. Сохраняются системные проблемы, 
связанные с контролем в отношении деятельности инновационных предпринимателей. Имеются в отдельных случаях несоответствия между инновационной политикой государства и политики в области образования, науки и технологий и т. д. Больше половины из перечня программ выше имеют ограниченные сроки действия. При этом принцип преемственности между завершенными и новыми программами поддержки практически не обеспечивается. Есть нарекания по отношению к системе мониторинга. Государственные органы привыкли оценивать эффективность программ по объемам освоенных средств.

Само по себе освоение средств не говорит о достижении качественных показателей в плане инновационного развития предпринимательства. Поэтому действующая система мониторинга и оценки эффективности должны быть усовершенствованы. В систему мониторинга и оценки должны быть включены целевые показатели, а государственные ведомства должны обратиться к практическому применению результатов оценки и мониторинга. В настоящее время Россия находится на переходном этапе к инновационной экономики. Перед органами власти стоит задача по решению накопившихся проблем системного характера. В основу инновационного типа экономики положено использование на производстве новых достижений в области науки и техники, выпуск высокотехнологичной продукции, ее поставка на внутренний и внешний рынок [6].

Для инновационной экономики большое значение имеет доля интеллектуального труда. Его большая доля в общей прибыли обеспечивает конкурентноспособность предприятий малого и среднего бизнеса. Проблему представляет финансирование инновационной деятельности предпринимателей. Финансирование для инновационных проектов в основном привлекается из государственных источников, а также за счет кредитования в банках. Новые технологии производства подразумевают необходимость больших вложений, зато с получением в долгосрочной перспективе большого дохода. Исследования ряда авторов указывают на то, что экономический рост государства напрямую зависит от технологического развития производства.

Становится очевидной необходимость использования мер стимуляции, включая меры государственной поддержки. Как было отмечено выше, в настоящее время в России действует целая система, направленная на предоставление комплексной поддержки для предпринимателей с целью стимулирования среди них инновационных процессов. Инновационная деятельность предпринимателей способна принести в долгосрочной перспективе весомый социально-экономический эффект, учитывая долю малых и средних предприятий в общей структуре российской экономики. В качестве лидеров по стимулированию инновационной деятельности предпринимателей рассматриваются такие страны, как США, Япония, Германия и т. д. Стратегия инновационного развития, которая продолжает реализовываться в России, была принята еще в 2011 г. Ею предусматривается работа государства сразу по нескольким направлениям, начиная от создания инфраструктуры под разработку и внедрение инновационных решений, заканчивая стимулированием инновационного бизнеса с выделением для субъектов малого и среднего бизнеса финансовой поддержки [7].

В основу комплексной системы поддержки инновационной деятельности предпринимателей в России был положен опыт других стран. В качестве конкурентных преимуществ для развития инновационной деятельности среди предпринимателей в России необходимо выделить: высокий научный потенциал (по разным оценкам он составляет 10-12\% от общемирового), активную роль государства в исследовательских и научных проектах, высокий уровень подготовки специалистов в области инженерии, развитую сеть из научно-исследовательских учреждений. Существуют факторы, которые негативно отражаются на развитии инновационной деятельности среди предпринимателей: низкий уровень предпринимательской инициативы, отставание большинства предприятий в плане технологий, неэффективность мер защиты интеллектуальных прав.

Поэтому оценивать инновационную среду нужно не только с позиции научно-кадрового потенциала, но и доли предпринимателей, которые участвуют в инновационной деятельности. Главной проблемой, названной выше, является недостаток финансирования. Инновационные проекты в области малого и среднего бизнеса лишь усиливают предпринимательские риски. Далеко не все из инновационных проектов способны окупиться и принести прибыль владельцам. Интерес среди предпринимателей к инновационным проектам остается низким за счет наличия высокодоходных видов бизнеса, где в целом не нужны какие-либо инновации. В частности, речь идет о торговле, сфере финансовой деятельности и т. д. Выходом из ситуации могут стать только меры поддержки со стороны государства. При этом поддержки государства в первую очередь должна быть оказана тем предпринимателям, чьи проекты имеют высокий коммерческий потенциал.

Инновационная деятельность предпринимателей подразумевает внедрение на производстве технологических изменений. Вслед за этим происходят качественные изменения в обществе в связи с обеспечением доступа населения к высокотехнологичной продукции. Меры поддержки в основном направлены на создание 
подходящих условий для тех предпринимателей, которые уже работают в области новых технологий. В течение последних лет была создана нормативно-правовая база для обеспечения реализации мер государственной поддержки инновационной деятельности предпринимателей. Через эту базу обеспечивается регулирование инновационных процессов, со стороны государства предусматривается выделение прямого финансирования для проектов. Достигнут прогресс в области создания соответствующей инфраструктуры для инновационной деятельности предпринимателей.

Российские власти более активно вмешиваются в инновационные процессы в сравнении с другими странами мира. Отчасти это можно объяснить тем, что еще с советского времени государство сохраняет за собой ведущую роль в области разработок и исследований. Привлечь к финансированию инновационных проектов предпринимателей частный капитал трудно, поскольку инвесторы заинтересованы на окупаемость инвестиций в краткосрочной или среднесрочной перспективе. В настоящее время для вовлечения предпринимателей в инновационные процессы разработан и внедрен системный подход. Через него оказывается инфраструктурная поддержка предпринимателям.

Кроме возможностей для выделения финансирования по упомянутым выше программам государство готово оказать техническую поддержку, предложить льготное налогообложение. При разработке и решении вопроса о выделении финансирования на проекты должна учитываться их социальная направленность. K примеру, в настоящее время общество заинтересовано во внедрении и использовании энергосберегающих технологий. Также общество заинтересовано в решении экологических проблем, появлении на рынке новых видов робототехники для автоматизации производства и процессов в быту. Удовлетворить такие потребности общества можно за счет углубления сотрудничества между научно-исследовательскими организациями и предпринимательским сообществом, за счет ведения реестра по инновационной деятельности в соответствии с международными требованиями.

С учетом ограниченности материальных ресурсов у малого и среднего бизнеса государством выработана нормативно-правовая база, которая предусматривает возможность создания малых инновационных предприятий. Уставным капиталом в них могут быть объекты интеллектуальной собственности. К настоящему времени остается пока нерешенным вопрос по снижению налоговых ставок в отношении тех субъектов предпринимательской деятельности, которые заняты инновационной деятельностью. Перспективным направлением является упрощение требований для ведения такими субъектами бухгалтерской и налоговой отчетности. Предприятиям малого и среднего бизнеса со стороны государства должна предоставляться поддержка по вопросам регистрации и последующей защиты прав на интеллектуальную собственность.

\section{Обсужмение}

Серьезное влияние на ситуацию с инновационным развитием оказывают условия макроэкономической страны. Что касается самой модели инновационного развития, то она не является новой, была выдвинута в начале 20-го века Шумпетером. Теория автора предполагает, что есть такие предприниматели, которые не готовы мириться с получением средней прибыли. С целью обеспечения ее роста они готовы пойти на дополнительные риски и вложить инвестиции в разработку и внедрение новых технологий. В теории рыночных условий низкая прибыль должна рассматриваться в качестве стимула для применения технологических инноваций. Российский опыт и опыт многих других стран показывает, что только рыночных механизмов недостаточно для того, чтобы способствовать активной инновационной деятельности предпринимателей.

\section{ЗакАючение}

Как показывает практика, патентная система с ее сборами не является совершенной. Поэтому предлагается на уровне государства разработать программу, по который в России были созданы специальные центры с целью продвижения патентов за рубежом. Этой же программой должно быть предусмотрено расширение перечня консультаций для тех субъектов, которые заинтересованы в переходе на инновационную деятельность. За счет этих мер удастся создать необходимую инновационную инфраструктуру. В ее создании в первую очередь заинтересован малый и средний бизнес.

На первом этапе со стороны государства для предпринимателей должна быть оказана вся необходимая помощь, начиная от консультаций и обеспечения доступа к техническим решениям, заканчивая выделением финансовой поддержки и экспертной оценкой подготовленного инновационного проекта. В настоящее время инфраструктура для инновационной деятельности среди предпринимателей представлена инновационными бизнес-инкубаторами (пока не получили широкого распространения), центров прототипирования, сообществ при региональных правительствах и т.д. Становится очевидным тот факт, что меры государственной поддержки для инновационной деятельности предпринимателей должна развиваться и стать всеобъемлющими, чтобы создать все условия для достижения социально-экономического роста. 


\section{ЛИТЕРАТУРА}

1. Пешина э.В., Авдеев П.А. Современные подходы к определению понятия и функций национальной инновационной системы // Управленец. - № 4 (50). 2018. - C. 9-19.

2. World Economic Forum (WEF). 2019. The Global Competitiveness Report Geneva: World Economic Forum. URL: http://www3.weforum.org/docs/WEF_GlobalComp etitivenessReport_2012-13.pdf

3. Цихан Т. Роль венчурной индустрии в формировании национальной инновационной системы. URL: http://forinsurer.com/public/04/11/29/1629

4. Пчелинцев В.С. Проблемы инновационной политики Швеции // Актуальные проблемы Европы. - 2017. - № 1. - С. 117-138.

5. К Клочихин Е.А. Научная и инновационная политика Китая // Международные процессы. -2016. - Т. 11. - № 2 (33). - С. 37-55.

6. Klochikhin, E.A. and Shapira. Engineering small worlds in a big society: Assessing the early impacts of nanotechnology in China // Review of Policy Research, 2015, no. 29 (6), pp. 752-775.

7. Стратегия развития науки и инноваций в Российской Федерации на период до 2015 года (протокол от 15.02.06). URL: http://ris.extech.ru/texts/strat_1.rtf

8. Концепция долгосрочного социально-экономического развития Российской Федерации на период до 2020 года (утв. распоряжение Правительства РФ от 17.11.2008 N 1662-p). URL: http://www.ifap.ru/ofdocs/rus/rus006.pdf

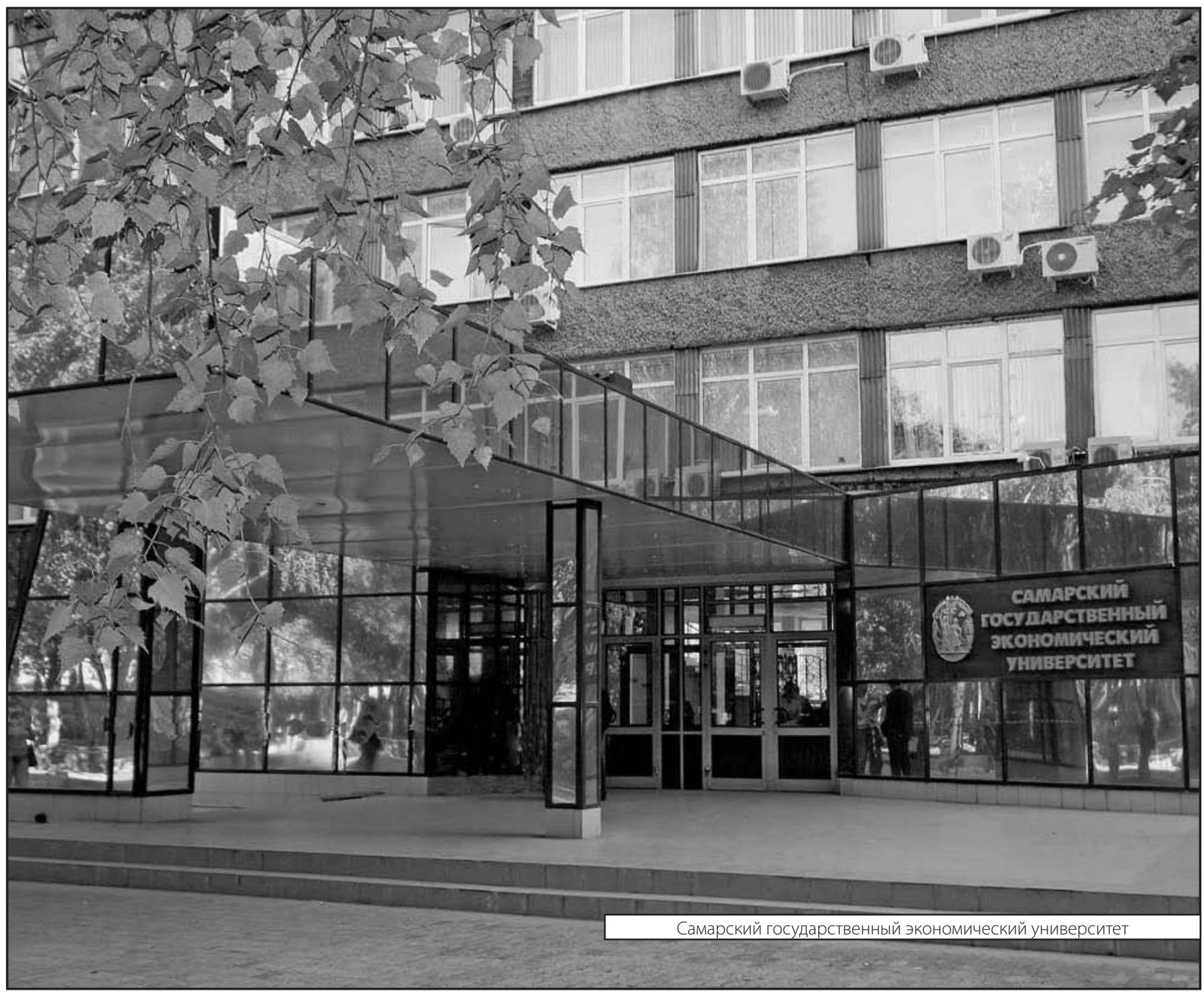

